\title{
Evaluation of "international transfer-out" among foreign-born pulmonary tuberculosis patients in Japan - what are the implications for a cross-border patient referral system?
}

\author{
Lisa Kawatsu* (10, Akihiro Ohkado, Kazuhiro Uchimura and Kiyohiko Izumi
}

\begin{abstract}
Background: Tuberculosis (TB) patients crossing borders pose a serious challenge to global TB control efforts. The objectives of our study were firstly, to evaluate the trend and size of foreign-born pulmonary TB patients, who had been notified and initiated treatment in Japan but have transferred out of the country while still on treatment; and secondly, to conduct a detailed analysis of these patients and identify possible risk factors for international transferout, and discuss policy implications for a cross-border patient referral system for foreign-born TB patients in Japan.

Methods: We conducted a cross-sectional study whereby aggregated cohort data of pulmonary TB cases newly notified to the Japan TB Surveillance system between 1 January 2011 and 31 December 2015 were analyzed. Multinomial logistic regression analysis was conducted to identify and compare the risk factors for international transfer-out.

Results: Among the 668 foreign-born patients whose treatment outcome had been evaluated as "transferred- out", 51.3\% has in fact moved to outside Japan between 2011 and 2015. The proportion of such international transferout of total foreign-born patients who had transferred out has more than doubled during the study period, from 23.3\% in 2011 to $57.7 \%$ in 2015. Some of the risk factors for international transfer-out were being a full-time worker (Relative risk [RR] 2.86, 95\% confidence interval [CI] 2.04, 3.99), being diagnosed within 0 to 2 years of arriving to Japan (RR 8.78, 95\% Cl 4.30,17.90) and within 3 to 5 years (RR $7.53,95 \% \mathrm{Cl} 3.61,15.68$ ), sputum smear positive (RR 1.95, 95\% Cl 1.53, 2.48), and coming from Indonesia (RR 1.86, 95\% Cl 1.13, 3.03).

Conclusions: Providing continuity of care for mobile population is one of the keys to achieving the WHO's End TB Strategy targets for 2030, and results of our study indicate that a cross-border referral system should be an integral part of TB control among foreign-born persons in Japan.
\end{abstract}

Keywords: Tuberculosis, Migration, Treatment outcome, Patient care, Surveillance

\footnotetext{
* Correspondence: kawatsu@jata.or.jp

Department of Epidemiology and Clinical Research, the Research Institute of

Tuberculosis, 3-1-24, Matsuyama Kiyose, Tokyo, Japan
}

(c) The Author(s). 2018 Open Access This article is distributed under the terms of the Creative Commons Attribution 4.0 International License (http://creativecommons.org/licenses/by/4.0/), which permits unrestricted use, distribution, and reproduction in any medium, provided you give appropriate credit to the original author(s) and the source, provide a link to the Creative Commons license, and indicate if changes were made. The Creative Commons Public Domain Dedication waiver (http://creativecommons.org/publicdomain/zero/1.0/) applies to the data made available in this article, unless otherwise stated. 


\section{Background}

The ever increasing movement of people across national borders has given rise to two particular issues in tuberculosis (TB) control; the first being the need for early case detection and diagnosis of $\mathrm{TB}$ being brought in from abroad, and the second, the need to ensure continuity of care for patients who have decided to move to another country while still on treatment. In response to the first, several countries have adopted screening programmes specifically targeting immigrants by means of chest-X ray, sputum examinations, tuberculin skin test or interferon-gamma assay $[1,2]$. On the other hand, establishing a system of cross-national patient referral, one of the possible solutions to addressing the second issues, has proved much more challenging [3].

Japan is a TB middle-burden country with 17,625 newly notified patients in 2016, giving a notification rate of 13.9 per 100,000 . Although the proportion of foreign-born persons among the total cases is relatively small compared to similarly industrialized countries, at $7.9 \%(n=1338)$ in 2016, between 2007 and 2016, both the number and the proportion have steadily increased approximately by 2.3 times, from $3.5 \%(n=842)$ to $7.9 \%(n=1338)$, and that among those aged 15 to 24 by 2.5 times, from $23.8 \%$ $(n=231)$ to $58.6 \%(n=471)$ [4].

In principle, $95 \%$ of the cost of $\mathrm{TB}$ treatment is covered by public subsidy for outpatients, and $100 \%$ for patients needing hospitalization, regardless of nationality. Directly Observed Treatment and patient education are provided in hospital settings for hospitalized patients, and in the community, generally by public health center (PHC) nurses, for outpatients. PHCs are local government bodies which are responsible for receiving notifications from physicians who have diagnosed $\mathrm{TB}$, registering them onto the national TB surveillance system, the Japan Tuberculosis Surveillance (JTBS), and managing treatment support for the patients (but not providing treatment). Yet several studies on treatment outcome and adherence behavior of foreign-born TB patients at national and sub-national level have indicated poorer performance as compared with Japan-born patients, with high proportions of those who have been "lost to follow-up" and have "transferred-out" $[5,6]$.

The current Japan Tuberculosis Surveillance (JTBS) system evaluates the treatment outcome as recorded by the PHC which initially registered the patient. Thus, when the patient moves out of its local jurisdiction, his/ her treatment outcome is recorded as "transferred-out". For domestic transfer-out, whereby patients move within Japan, most patients are usually transferred-in and continue and complete their treatment [7]. However, as for international transfer-out, whereby patients move out of Japan, there is currently no standardized system or procedures for referring foreign-born patients to medical institutions in the country of their origin. Cross-national patient referral has been organized on several occasions but on an ad-hoc basis, and treatment outcome is usually not followed-up [8].

Considering that foreign-born persons moving both in and out of Japan are likely to continue to increase, and also the growing threat of drug-resistant TB due in sufficient patient care, the potential impact of international transfer-out cannot be underestimated. Yet to date, no study has attempted to evaluate the size of foreign-born patients transferring out of Japan while still on TB treatment. In this study, we thus firstly sought to evaluate the trend and size of international transfer-out among the foreign-born pulmonary TB (pTB) patients, who had been notified to the JTBS and who had initiated treatment in Japan. Secondly, we attempted a detailed analysis of those who have transferred out of Japan, and identify possible risk factors for international transfer-out, and discuss whether there are any policy implications for a crossborder patient referral system for foreign-born TB patients in Japan.

\section{Method}

We conducted a cross-sectional study whereby aggregated cohort data of PTB cases newly notified to the JTBS between 1 January 2011 and 31 December 2015 were analyzed. Those whose country of birth was recorded as "unknown" were excluded from the analysis.

Under the JTBS, treatment outcome of drug-susceptible pTB patients is evaluated at the end of 12 months. The outcome categories include "cured", "treatment completed", "died", "treatment failure", "lost to follow-up", "transferred out", "still on treatment", and "unevaluated" [4]. "Transferred out" includes both transfer within and to outside Japan, and are not disaggregated in the analysis of treatment outcome. A more detailed information regarding the system, and various definitions can be found elsewhere [4]. In evaluating the size of "international transfer-out", we thus turned to another variable of the JTBS, namely, the "reason for de-registering" from the TB registry. PHC which initially received the notification de-registers the patient from its TB registry when he or she has been transferred and in doing so, is asked to enter the reason for de-registering the patient from the following options; "follow-up no longer required", "died due to TB", "died due to non-TB cause", "not diagnosed as TB", "domestic transfer-out", "international transfer-out", "re-registered as either new active TB case or LTBI during follow-up" and "others". We thus firstly disaggregated those who have been evaluated as "transferred out" under treatment outcome category by "reason for de-registering", to evaluate the actual and proportional size of "international transfer-out", and its trend during the study period. 
Secondly, we attempted a detailed analysis of those foreign-born patients who have transferred outside Japan, by examining and comparing their socio-demographic characteristics with foreign-born patients who have successfully completed treatment, and those who have been lost to follow-up, and those who have transferred outside of Japan. For the purpose of our analysis, those whose treatment outcome was recorded as "cured", "treatment completed", and "transferred out" but whose reason for being de-registered was domestic transfer-out, were combined as "treatment success". We then conducted a multinomial logistic regression analysis, taking "treatment success", "international transfer-out" and "lost to follow-up" as outcomes, to identify possible risk factors for international transfer-out.

Based on previous studies, and the practical availability from the JTBS dataset, the following were chosen as independent variables; sex, age groups, occupational category (regrouped into "high school and university students", "full-time employed workers", "temporary and day workers", "unemployed" and "others"), number of years between entry to Japan and being diagnosed as TB in Japan, sputum smear examination result, and countries of birth. We also examined the timing at which patients had moved out of Japan by counting the day from when treatment was initiated to when the patient was de-registered. The $\mathrm{R}$ version 3.1.3 (R Development Core Team, Vienna, Austria) was used for all statistical analyses.

\section{Results}

Size and trend of "international transfer-out" among foreign-born pTB patients.

Flow-chart of the study population is shown in Fig. 1. The treatment outcome was known for 4179 foreign-born patients who had been notified to the JTBS between 2011 and 2015, and is summarized in Table 1, by age groups. Of the total 4179 foreign-born patients, 668 had been evaluated as "transferred out". Analysis of the reason for deregistering from the TB registry among the 668 foreign-born patients who had been evaluated as "transferred out" revealed that $51.3 \%(n=343)$ has in fact moved to outside Japan, with the highest proportion of international transfer-out among those between aged 15 and 24 years old $(10.9 \%, 145 / 1330)$.

The proportion of international transfer out of total foreign-born patients who had been evaluated as "transferred out" has more than doubled during the study period, from $23.3 \%$ in 2011 to $57.7 \%$ in 2015 , as shown in Fig. 2 (see also Additional file 1).

Characteristics of foreign-born pTB patients who have transferred-out.

The socio-demographic characteristics of foreign-born patients who have transferred outside of Japan $(n=343)$ are summarized and compared with those lost to follow-up
( $n=259)$, and those who have successfully completed treatment in Japan (i.e. "completed", "cured", and "domestic transfer-out", $n=2878$ ), in Table 2. Among those who have transferred out, the proportion of males and of those aged between 0 and 24 years old were higher as compared to those who were lost to follow-up and those who have successfully completed treatment (59.25 vs 42.1 and $47.8 \%, 42.6 \%$ vs $25.9,33.7 \%)$. Among those who have transferred out, the largest occupational category was "full-time workers" (42.6\%), followed by "unemployed" (21.3\%). However, among those lost to follow-up and those who have successfully completed treatment, the largest group was similarly "full-time workers" (36.7 and $33.9 \%$ ), but followed by "high school and university students" (22.8 and 30.0\%). Among those who have transferred out, $40.8 \%$ had arrived in Japan within 2 years of being diagnosed, while the proportion was much smaller among those lost to follow-up and those who have successfully completed treatment (22.4 and $24.1 \%)$. The proportion of smear positive upon diagnosis was also higher among those who have transferred out, in contrast to those lost to follow-up and those who have successfully completed treatment (52.2\% vs 22.0 and 38.1\%). Finally, while China and the Philippines together contributed to approximately half of the country of birth for all treatment outcome groups, the proportion of those from Indonesia was notably higher among those who have transferred out, than those lost to follow-up and those who have successfully completed treatment (11.1\% vs 3.1 and $4.9 \%)$.

\section{Risk factors for "international transfer-out"}

Table 3 summarizes the results of the multinomial logistic regression analysis, taking "treatment success" as reference. Among those who have transferred out, males were at a higher risk of transferring out compared with females (relative risk [RR] 1.54, 95\% confidence interval [CI]1.21,1.97). Similarly, taking students as reference, being a full-time worker (RR 3.01, 95\% confidence interval [CI] 2.14, 4.23), temporary worker (RR 2.84, 95\% CI 1.78, 4.54), unemployed (RR 3.40, 95\% CI 2.21, 5.22) and others (RR 2.34, 95\% CI 1.34, 4.10) were identified as risk factors for international transfer-out. As for time between entry to Japan and diagnosis, taking "more than 10 years" as reference, those patients who had been diagnosed within 0 to 2 years (RR 8.78, 95\% CI 4.30, 17.90), within 3 to 5 years (RR 7.53, 95\% CI 3.61, 15.68), and unknown (RR 3.70, 95\% CI 1.84, 7.43) were at a significant risk of transferring out of Japan. Taking negative result for sputum smear examination, a positive result (RR 1.95, 95\% CI 1.53, 2.48), and coming from Indonesia (RR 1.86, 95\% CI 1.13, 3.03) were also identified as risk factors. On the other hand, being aged between 25 and 54 years old (RR 0.71, 95\% CI 0.54-0.93) and coming from Nepal (RR 0.28 95\% CI 0.12, 0.63) were identified as protective factors for international transfer-out. 
Cohort data of patients with pulmonary tuberculosis, notified between 2011 and 2015

$n=78,902$

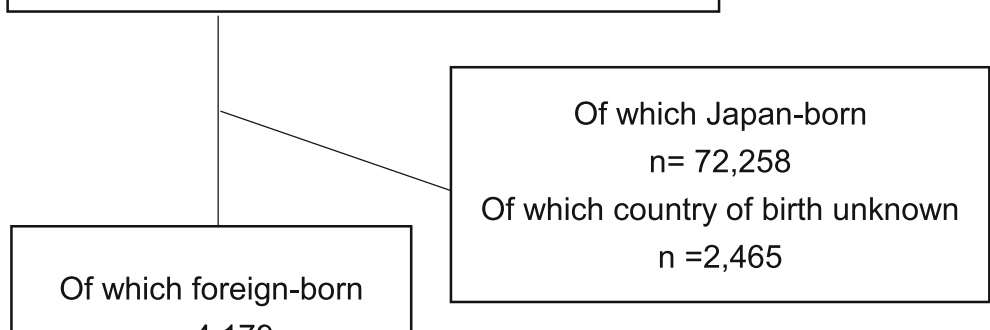

$n=4,179$

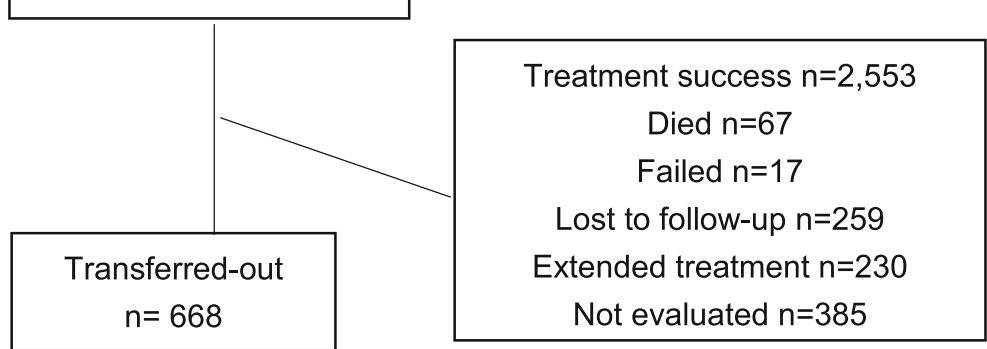

transfer

$n=343$

Fig. 1 Flow-chart of the study population

Table 1 Treatment outcomes of foreign-born pTB patients by age groups, 2011-2015

\begin{tabular}{|c|c|c|c|c|c|c|c|c|c|c|}
\hline & \multicolumn{2}{|c|}{$0-14$} & \multicolumn{2}{|c|}{$15-24$} & \multicolumn{2}{|c|}{$25-54$} & \multicolumn{2}{|l|}{$55+$} & \multicolumn{2}{|l|}{ Total } \\
\hline & $n$ & $\%$ & $n$ & $\%$ & $n$ & $\%$ & $n$ & $\%$ & $\mathrm{n}$ & $\%$ \\
\hline Completed & 16 & 76.2 & 589 & 44.3 & 1217 & 49.7 & 115 & 30.3 & 1937 & 46.4 \\
\hline Cured & 0 & 0.0 & 217 & 16.3 & 345 & 14.1 & 54 & 14.2 & 616 & 14.7 \\
\hline Died & 0 & 0.0 & 0 & 0.0 & 13 & 0.5 & 54 & 14.2 & 67 & 1.6 \\
\hline Failed & 0 & 0.0 & 3 & 0.2 & 9 & 0.4 & 5 & 1.3 & 17 & 0.4 \\
\hline Lost to follow-up & 0 & 0.0 & 67 & 5.0 & 169 & 6.9 & 23 & 6.1 & 259 & 6.2 \\
\hline Not evaluated & 3 & 14.3 & 110 & 8.3 & 233 & 9.5 & 39 & 10.3 & 385 & 9.2 \\
\hline Still on treatment & 0 & 0.0 & 51 & 3.8 & 140 & 5.7 & 39 & 10.3 & 230 & 5.5 \\
\hline International transfer-out & 1 & 4.8 & 145 & 10.9 & 165 & 6.7 & 32 & 8.4 & 343 & 8.2 \\
\hline Domestic transfer-out & 1 & 4.8 & 148 & 11.1 & 158 & 6.5 & 18 & 4.7 & 325 & 7.8 \\
\hline Total & 21 & 100.0 & 1330 & 100.0 & 2449 & 100.0 & 379 & 100.0 & 4179 & 100.0 \\
\hline
\end{tabular}

PTB pulmonary tuberculosis 


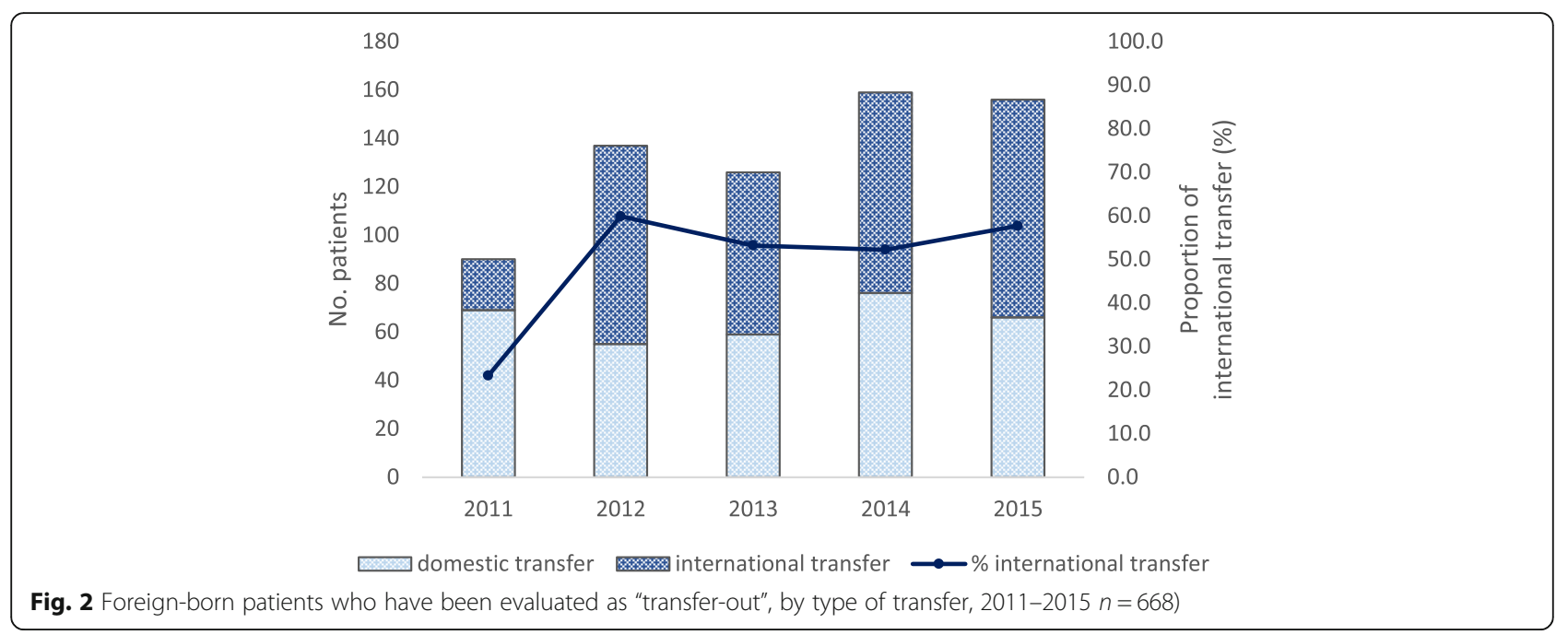

None of the variables which had been identified as risk factors for international transfer-out were significant factors for lost to follow-up. In fact, the only statistically significant variable which was identified for lost to follow-up was a sputum smear examination result, but with relative risk pointing towards the opposite direction - in other words, being smear positive was identified as a protective factor (RR 0.42, 95\% CI 0.31, 0.57).

\section{Timing of transfer-out}

Out of 343 foreign-born patients who had transferred out of Japan, the treatment duration was known for 142 . Figure 3 shows that while $66.9 \%$ 95/142) had transferred out after 60 days, $33.1 \%$ 47/142) did so in their intensive phase. Furthermore, $8.5 \% \quad n=12$ ) had transferred out within 10 days of being notified see also Additional file 2). Of the 47 who transferred out in their intensive phase, $40.4 \% n=19)$ were sputum smear positive, indicating that they may have moved out while they were still being hospitalized i.e. before confirmation of negative conversion.

\section{Discussion}

This study is the first ever attempt to have focused specifically on foreign-born TB patients transferring out of Japan while still on treatment for TB at a national level. Our results have shown that over the study period, $8.2 \%$ 343/4179) of the total foreign-born pTB patients had moved out of Japan during their treatment, and their final treatment outcomes were unknown. Those with some sort of work, those unemployed, those who have recently arrived in Japan, those smear positive and those coming from Indonesia were at a higher risk of transferring out of Japan.

The results are reasonable in that compared with students, employed persons are more likely to have the financial capacity to pay for their travel back to their home country. A recent study on the economic situation of foreign-born students in Japan has indicated that of the total respondents, as much as $74.8 \%$ had to work outside the school hours to maintain their living, and that 33.5\% were working more than $20 \mathrm{~h}$ a week [9]. Thus, even if they had wanted to, it would probably be difficult for many to travel back to their countries of origin. Employed persons, on the other hand, would be in a position to choose from a wider selection of options, including completing their treatment in their home country. This also explains the differences by countries of origin - for example, the proportion of those from Indonesia entering with student visa is relatively small compared with other nationalities, at approximately $15 \%$ [10]. The majority arrive to Japan with some sort of employment or internship visa, and are therefore more likely to be able to return to their country for completing TB treatment, should they wish to do so. On the other hand, approximately $60 \%$ of those from Nepal enter Japan as students, many of whom are students of private Japanese language schools and training colleges, and are thus self-funded [10, 11].

Those who have recently arrived in Japan are more likely to face linguistic, cultural and social difficulties in continuing the treatment in Japan. Inadequate medical and welfare support for foreign-born patients is increasingly raised as a serious issue and has been pointed out in numerous studies [12-14]. In a similar study on treatment outcome of foreign-born TB patients in Osaka, time of entry to Japan within 5 years of being diagnosed was also identified as a risk factor for international transfer-out [6]. Furthermore, in Japan, patients who have tested positive for sputum smear examination are required to be hospitalized until they are proved no longer infectious. It is thus quite understandable that sputum-smear positive foreign-born patients who are 
Table 2 Characteristics of foreign-born patients who have transferred outside of Japan, who have been lost to follow-up, and who have successfully completed treatment, 2011-2015

\begin{tabular}{|c|c|c|c|c|c|c|}
\hline & \multicolumn{2}{|c|}{ International transfer-out } & \multicolumn{2}{|c|}{ Lost to follow-up } & \multicolumn{2}{|c|}{ Treatment success } \\
\hline & $n$ & $\%$ & $n$ & $\%$ & $n$ & $\%$ \\
\hline Total & 343 & 100 & 259 & 100 & 2878 & 100 \\
\hline \multicolumn{7}{|l|}{ Sex } \\
\hline Male & 203 & 59.2 & 109 & 42.1 & 1376 & 47.8 \\
\hline Female & 140 & 40.8 & 150 & 57.9 & 1502 & 52.2 \\
\hline \multicolumn{7}{|l|}{ Age groups (years) } \\
\hline $0-24$ & 146 & 42.6 & 67 & 25.9 & 971 & 33.7 \\
\hline $25-54$ & 165 & 48.1 & 169 & 65.3 & 1720 & 59.8 \\
\hline 54-plus & 32 & 9.3 & 23 & 8.9 & 187 & 6.5 \\
\hline \multicolumn{7}{|l|}{ Occupational status } \\
\hline High school and university students & 65 & 19.0 & 59 & 22.8 & 864 & 30.0 \\
\hline Full-time workers & 146 & 42.6 & 95 & 36.7 & 977 & 33.9 \\
\hline Temporary employed/day workers & 37 & 10.8 & 28 & 10.8 & 302 & 10.5 \\
\hline Unemployed & 73 & 21.3 & 54 & 20.8 & 467 & 16.2 \\
\hline Others, including unknown & 22 & 6.4 & 23 & 8.9 & 268 & 9.3 \\
\hline \multicolumn{7}{|c|}{ Time between entry to Japan and diagnosis (years) } \\
\hline $0-2$ & 140 & 40.8 & 58 & 22.4 & 694 & 24.1 \\
\hline $3-5$ & 67 & 19.5 & 35 & 13.5 & 364 & 12.6 \\
\hline $5-10$ & 5 & 1.5 & 19 & 7.3 & 213 & 7.4 \\
\hline $10+$ & 9 & 2.6 & 36 & 13.9 & 301 & 10.5 \\
\hline Unknown & 122 & 35.6 & 111 & 42.9 & 1306 & 45.4 \\
\hline \multicolumn{7}{|l|}{ Sputum smear } \\
\hline Negative & 158 & 46.1 & 194 & 74.9 & 1742 & 60.5 \\
\hline Positive & 179 & 52.2 & 57 & 22.0 & 1096 & 38.1 \\
\hline Not done/Unknown & 6 & 1.7 & 8 & 3.1 & 40 & 1.4 \\
\hline \multicolumn{7}{|l|}{ Country of birth } \\
\hline Others & 53 & 15.5 & 46 & 17.8 & 533 & 18.5 \\
\hline China & 115 & 33.5 & 72 & 27.8 & 810 & 28.1 \\
\hline Indonesia & 38 & 11.1 & 8 & 3.1 & 142 & 4.9 \\
\hline Korea & 15 & 4.4 & 15 & 5.8 & 172 & 6.0 \\
\hline Nepal & 7 & 2.0 & 15 & 5.8 & 218 & 7.6 \\
\hline Philippines & 65 & 19.0 & 70 & 27.0 & 695 & 24.1 \\
\hline Thailand & 8 & 2.3 & 12 & 4.6 & 63 & 2.2 \\
\hline Vietnam & 42 & 12.2 & 21 & 8.1 & 245 & 8.5 \\
\hline
\end{tabular}

told that they need to be hospitalized face even greater anxiety, and feel less confident about continuing their treatment in Japan.

Interestingly, sputum smear positive result was identified as a protective factor for lost to follow-up - however, this is consistent with a study on the risk factors for lost to follow-up in Japan. The authors have argued that the perceived "seriousness" of the disease on part of the patients, together with intensive patient education they receive during hospitalization, may make these patients less prone to treatment interruption [15]. Perhaps a detailed qualitative analysis should follow to explore why some smear positive foreign-born patients decide to return to their home country, while others decide to stay in Japan to complete their treatment. What our results do indicate is that a different approach is needed to address international transfer-out, to that required for foreign-born patients becoming lost to follow-up in Japan.

It is certainly not the intention of the authors to argue that these patients should complete their treatment in 
Table 3 Relative risks for international transfer-out and lost to follow-up

\begin{tabular}{|c|c|c|c|c|c|c|}
\hline & \multicolumn{3}{|c|}{ International transfer-out } & \multicolumn{3}{|c|}{ Lost to follow-up } \\
\hline & Relative Risk & $95 \% \mathrm{Cl}$ & $P$ value & Relative Risk & $95 \% \mathrm{Cl}$ & $P$ value \\
\hline \multicolumn{7}{|l|}{ Sex } \\
\hline Female & Reference & & & & & \\
\hline Male & 1.54 & $1.21-1.97$ & $<0.01$ & 0.83 & $0.63-1.09$ & 0.18 \\
\hline \multicolumn{7}{|l|}{ Age groups (years) } \\
\hline $0-24$ & Reference & & & & & \\
\hline $25-54$ & 0.71 & $0.54-0.93$ & 0.01 & 1.32 & $0.94-1.86$ & 0.11 \\
\hline $54+$ & 1.10 & $0.65-1.85$ & 0.72 & 1.74 & $0.95-3.18$ & 0.07 \\
\hline \multicolumn{7}{|l|}{ Occupational status } \\
\hline High school and university students & Reference & & & & & \\
\hline Full-time workers & 3.01 & $2.14-4.23$ & $<0.01$ & 1.33 & $0.90-1.95$ & 0.15 \\
\hline Temporary employed/day workers & 2.84 & $1.78-4.54$ & $<0.01$ & 1.29 & $0.77-2.16$ & 0.33 \\
\hline Unemployed & 3.40 & $2.21-5.22$ & $<0.01$ & 1.58 & $0.99-2.52$ & 0.06 \\
\hline Others, including unknown & 2.34 & $1.34-4.10$ & $<0.01$ & 1.19 & $0.68-2.08$ & 0.54 \\
\hline \multicolumn{7}{|c|}{ Time between entry to Japan and diagnosis (years) } \\
\hline $10+$ & Reference & & & & & \\
\hline $0-2$ & 8.78 & $4.30-17.90$ & $<0.01$ & 0.93 & $0.57-1.51$ & 0.76 \\
\hline $3-5$ & 7.53 & $3.61-15.68$ & $<0.01$ & 1.00 & $0.59-1.67$ & 0.90 \\
\hline $5-10$ & 0.91 & $0.30-2.79$ & 0.87 & 0.79 & $0.44-1.44$ & 0.44 \\
\hline Unknown & 3.70 & $1.84-7.43$ & $<0.01$ & 0.79 & $0.52-1.19$ & 0.26 \\
\hline \multicolumn{7}{|l|}{ Sputum smear } \\
\hline Negative & Reference & & & & & \\
\hline Positive & 1.95 & $1.53-2.48$ & $<0.01$ & 0.42 & $0.31-0.57$ & $<0.01$ \\
\hline Not done/Unknown & 1.55 & $0.62-3.85$ & 0.35 & 1.83 & $0.84-3.99$ & 0.13 \\
\hline \multicolumn{7}{|l|}{ Country of birth } \\
\hline Others & Reference & & & & & \\
\hline China & 1.32 & $0.91-1.89$ & 0.14 & 1.11 & $0.75-1.66$ & 0.60 \\
\hline Indonesia & 1.86 & $1.13-3.03$ & 0.01 & 0.66 & $0.30-1.46$ & 0.31 \\
\hline Korea & 0.78 & $0.42-1.46$ & 0.44 & 0.94 & $0.50-1.75$ & 0.84 \\
\hline Nepal & 0.28 & $0.12-0.63$ & $<0.01$ & 1.02 & $0.54-1.90$ & 0.96 \\
\hline Philippines & 0.90 & $0.60-1.34$ & 0.60 & 1.07 & $0.71-1.61$ & 0.74 \\
\hline Thailand & 1.40 & $0.62-3.12$ & 0.42 & 2.19 & $1.08-4.41$ & 0.03 \\
\hline Vietnam & 1.53 & $0.96-2.43$ & 0.07 & 1.11 & $0.63-1.94$ & 0.72 \\
\hline
\end{tabular}

$\mathrm{Cl}$ confidence interval

Japan, or that the option of completing the treatment in Japan is better than that of returning to their home country. What is an issue is that when foreign-born patients decide to move out of Japan, such cross-border referral is not conducted systematically and their ultimate treatment outcomes remain unknown. Several studies have shown that mobility is a significant risk factor for treatment interruption [16], and consequently for development of drug resistance $[17,18]$.

Though still limited, several countries have begun to address the issue of continuation of care for patients leaving their country. In the Netherlands, its Tuberculosis Control Plan 2016-2020 clearly states that concerted effort to ensure that TB patients who leave the Netherlands during their treatment are referred to treatment providers in the destination countries, and KNCV Tuberculosis Foundation began monitoring and documenting the outcomes of this process [3]. Within Europe, the European Respiratory Society and the WHO Regional Office for Europe have also jointly developed a web-based, open-access multi-lingual system, TB Consilium, with a function to introduce a patient to a treatment provider in another country [19]. The 


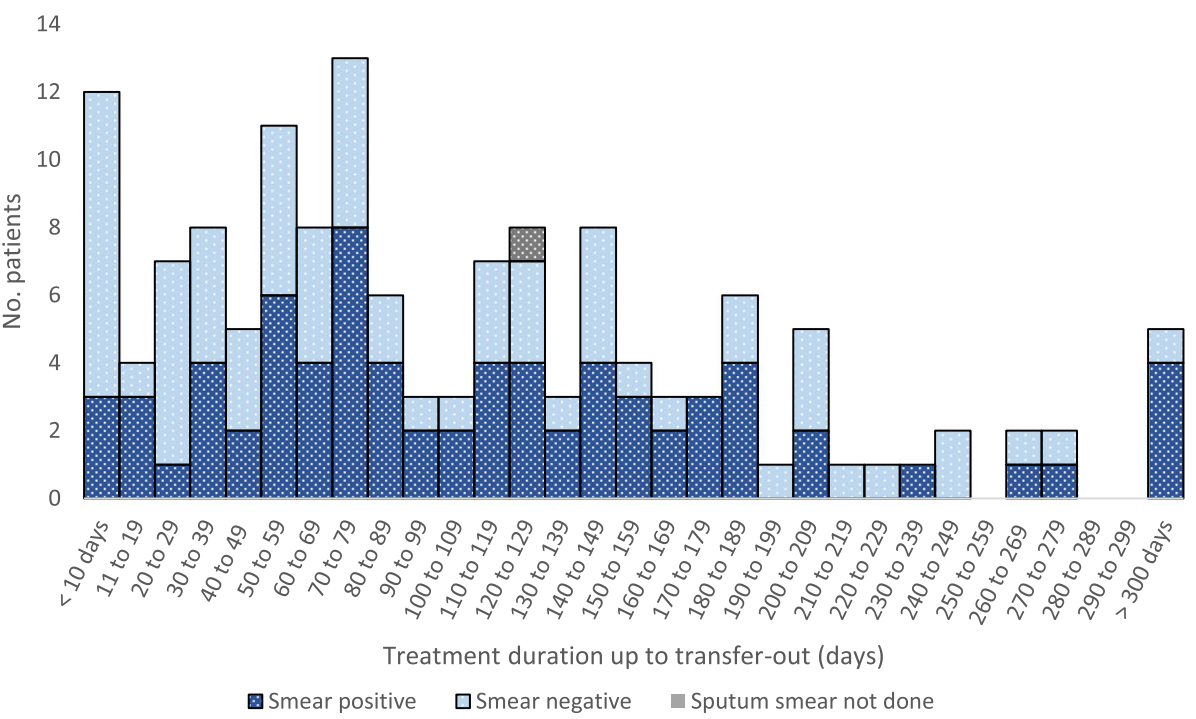

Fig. 3 Treatment duration up to transfer-out, in days

United States Cure TB Program, which is a federally funded program by San Diego TB Control Program and now an official partner with the Center for Disease Prevention and Control, has been systematically providing binational United States and Mexico) referral services since 1997, and has recently expanded their program to cover the rest of the world $[20,21]$. Another non-profit organization, Migrant Clinicians Network, has also been serving mobile patients with health needs since 1996. Their services include transfer of medical records, follow-up and other patient support, and as for TB, has consistently reported treatment completion rate of more than $84 \%$ [22]. Furthermore, a recent modelling study has indicated that a scale-up of these cross-border referral services would not only benefit the patients themselves, but also the Unites States directly, as well as the international community at large [20]. Results of our study indicate that such a cross-border referral system is necessary in Japan too-a small pilot project with countries with relatively large number of returning patients, such as China, the Philippines and Vietnam, may be considered.

This study is not without limitations. Firstly, the analysis of timing of transfer-out was only possible for slightly less than a half of those patients who had been recorded as "international transfer-out". Furthermore, the claim that patients have moved out of Japan is not in any way confirmed by, for example, airplane tickets or official documents, and is based on self-report. It is thus quite possible that a patient, having informed the public health center of his or her intention of going back to country of origin, in fact continues to stay in Japan. Secondly, the data analyzed only covered drug-susceptible pTB patients - a detailed analysis of patients with multi-drug resistance, as well as extrapulmonary TB, ought to follow. The strength of this study is that it uses the data from a national surveillance system, with relatively high data entry rate [4]. Furthermore, data quality is assured via a variety of mechanisms including the system's internal verification program [4] - it is thus reasonable to claim credibility of the data and generalizability of our results.

\section{Conclusions}

Unigonorable number of foreign-born TB patients are moving out of Japan while still on treatment, with their final treatment outcome unknown. Some of them were sputum smear positive, and had moved shortly after being diagnosed. These patients present immediate concern of the risk of causing secondary infection, and of themselves interrupting treatment, as well as mid-to long-term concern of exacerbating anti-microbial resistance in the world. It is without doubt that providing continuity of care for mobile population is one of the keys to achieving the WHO's End TB Strategy targets for 2030, and it is about time Japan gets its act together in building a cross-border referral system for foreign-born patients who are diagnosed in Japan. Such a system can be started out as a small pilot project with countries to which relatively large number of patients are returning, such as China, the Philippines and Vietnam, and be expanded gradually.

\section{Additional files}

Additional file 1: Trend in the number and proportion of international transfer-out, 2011-2015. A table showing the number of domestic and international transfer out. (XLSX $11 \mathrm{~kb}$ )

Additional file 2: Timing of international transfer-out. A table showing the number of days between treatment initiation and de-registration from TB registry, of foreign-born patients who have transferred outside Japan, by sputum smear examination result. (XLSX 14 kb) 


\section{Acknowledgements}

The authors would like to acknowledge all those who contributed to notifying and registering information on TB patients in Japan, including physicians, public health nurses, microbiologists and administrative staff.

\section{Funding}

Not applicable.

\section{Availability of data and materials}

The surveillance data that support the findings of this study are available from the Tuberculosis Surveillance Center http://www.jata.or.jp/rit/ekigaku/en) but restrictions apply to the availability of raw data. Raw surveillance data was used under license for the current study, and is not publicly available. Aggregated data is however available from the authors upon reasonable request and with permission of the Tuberculosis Surveillance Center.

\section{Authors' contributions}

LK and UK initiated and designed the study. LK analyzed the data, and LK, UK, $\mathrm{AO}$ and $\mathrm{KI}$ were responsible for discussing the results and conclusions. LK was responsible for writing up, and UK, $\mathrm{AO}$ and $\mathrm{KI}$ contributed by reading the draft, providing comments and revising as necessary. LK, UK, AO and KI all gave approval for the final version to be published.

\section{Ethics approval and consent to participate}

The study was approved by the Institutional Review Board of the Research Institute of Tuberculosis, Japan Anti-Tuberculosis Association reference number RIT/IRB 29-25). Informed consent was deemed not necessary by the above mentioned Review Board as the surveillance data does not contain personal identifiers.

\section{Consent for publication}

Not applicable.

\section{Competing interests}

The authors declare that they have no competing interests.

\section{Publisher's Note}

Springer Nature remains neutral with regard to jurisdictional claims in published maps and institutional affiliations.

Received: 1 August 2018 Accepted: 27 November 2018 Published online: 07 December 2018

\section{References}

1. Aldridge R, Yates T, Zenner D, White P, Abubaker I, Hayward A. Pre-entry screening programmes for tuberculosis in migrant to low-incidence countries; a systematic review and meta-analysis. Lancet Infect Dis. 2014;14:1240-9.

2. Klinkenberg E, Manissero D, Semenza C, Verver S. Migrant tuberculosis screening in the EU/EEA: yield, coverage and limitations. Eur Respir J. 2009;34:1180-9.

3. Dara M, Sulis G, Centis R, D'Ambrosio L, de Vries G, Douglas P, Garcia D, Jansen N, Zuroweste E, Migloiro G. Cross-border collaboration for improved tuberculosis prevention and care: policies, tools and experiences. Int J Tuberc Lung Dis. 2017;21:727-36.

4. Tuberculosis in Japan -. annual report 2016. Tokyo, Tuberculosis Surveillance Center, Department of Epidemiology and Clinical Research, the Research Institute of Tuberculosis. http://www.jata.or.jp/rit/ekigaku/en/ statistics-of-tb/. Accessed 8 July 2017.

5. Kawatsu L, Uchimura K, Izumi K, Ohkado A, Ishikawa N. Profile of tuberculosis among the foreign-born population in Japan, 2007-2014. Western Pac Surveill Response J. 2016;7:7-16.

6. Tsuda Y, Matsumoto K, Komukai J, Kasai S, Warabino Y, Hirota S, Koda S, Shimouchi A. Pulmonary tuberculosis treatment outcome among foreign nationals residing in Osaka City. Kekkaku. 2015;90:387-93 in Japanese.

7. Kawatsu L, Ohkado A, Uchimura K, Izumi K. Analysis of those "transferred-out" among pulmonary tuberculosis patients in Japan. Kekkaku. 2018;93. In print.

8. Ohkado A. Nihon kara Philippines heno kekkaku kanja shoukai jireikentou kakujituna kekkaku chiryou notameno torikumi, "Cross-border tuberculosis patient referral - a case of Japan-Philippines referral") Hokenshi/Kangoshi no Kekkaku Tenbo. 2017;55:33-9. in Japanese.
9. Heisei 27 nendo shihi gaikokujin ryugakusei seikatu jittai chousa, "Survey on livelihood of self-funded foreign-born students studying in Japan, 2015". Tokyo: Student Services Organization; 2016. https://www.jasso.go.jp/about/ statistics/ryuj_chosa/h27.html. Accessed 10 July 2018.

10. Heisei 27 nendo gaikoku jin ryugakusei zaiseki jousei chousa, "Survey on affiliation of foreign-born students studying in Japan, 2015". Tokyo: Student Services Organization; 2016. https://www.jasso.go.jp/about/statistics/intl_ student_e/2015/index.html. Accessed 10 July 2018.

11. Kawatsu L, Uchimura K, Izumi K, Ohkado A, Kato S. Using surveillance data to simulate the impact of a hypothetical pre-entry tuberculosis screninng programme in Japan. Int J Tuberc Lung Dis. 2018;22:510-7.

12. Tanaka Y, Kato K, Uehara J, Uto M, Nakamura Y. Hokeniryo kikan niokeru gaikokujin taiou no genjou to kadai - Mieken no byouin oyobi shichou hoken Senta wo taisho toshita zenken chousa yori, "a survey on the needs for medical and health-related services for foreign-born persons in hospitals and public health centers in Mie prefecture"). Jpn Soc Travel Health. 2018; 11:74-80. in Japanese.

13. Hamai T, Nagata A, Nishikawa H. The need for medical interpreters: a questionnaire survey of municipal hospitals in Japan. Jpn J Public Health. 2017;64:672-83. in Japanese.

14. Watanabe A, Sakka L. Listening to foreign patient voices: a narrative approach. J interdisciplinary res. 2017;17:1-11.

15. Kawatsu L, Uchimura K, Ohkado A, Kato S. A combination of quantitative and qualitative methods in investigating risk factors for lost to follow-up for tuberculosis treatment in Japan - are physicians and nurses at a particular risk? PLoS One. 2018;13(6):e0198075. https://doi.org/10.1371/journal.pone. 0198075. eCollection 2018

16. Abarca Tomás B, Pell C, Bueno Cavanillas A, Guillén Solvas J, Pool R, Roura M. Tuberculosis in migrant populations. A systematic review of the qualitative literature. PLoS One. 2013;8:e82440.

17. Dhavan P, Mosca D. Tuberculosis and migration: a post-2015 call for action. Migration Policy Practice Journal. 2014;IV:17-22.

18. Centers for Disease Control and Prevention. Post-detention completion of tuberculosis treatment for persons deported or released from the custody of the immigration and naturalization service—United States, 2003. MMWR Morb Mortal Wkly Rep. 2003;52:438-41.

19. Blasi F, Dara M, van der Werf MJ, Migliori GB. Supporting TB clinicians managing difficult cases: the ERS/WHO Cosilium. Eur Respir J. 2013;41:491-4.

20. Tschampl C, Garnick D, Zuroweste E, Razavi M, Shepard D. Use of transnational services to prevent treatment interruption in tuberculosis-infected persons who leave the United States. Emerg Infect Dis. 2016;22:417-25.

21. Vera-Garcia C. Managing cases across borders: US, Mexico and Central America. Presented at: $18^{\text {th }}$ annual conference, international union of against tuberculosis and lung disease - North America Region; 2014 Feb 26- Mar 1; Boston, Massachusetts, USA.

22. Zuroweste T. TBNet stas 2005-2012. Presented at: Annual Meeting of the National Tuberculosis Controllers Association; 2014 Jun 11-14, Atlanta, Georgia , USA.

Ready to submit your research? Choose BMC and benefit from:

- fast, convenient online submission

- thorough peer review by experienced researchers in your field

- rapid publication on acceptance

- support for research data, including large and complex data types

- gold Open Access which fosters wider collaboration and increased citations

- maximum visibility for your research: over $100 \mathrm{M}$ website views per year

At BMC, research is always in progress.

Learn more biomedcentral.com/submissions 